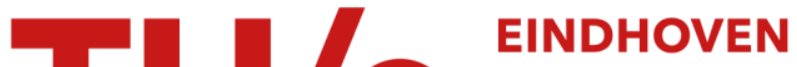 UNIVERSITY OF TECHNOLOGY
}

\section{Increased bit rate direct modulation AMO-OFDM transmission by optical injection using monolithically integrated lasers}

\section{Citation for published version (APA):}

Browning, C., Shi, K., Latkowski, S., Anandarajah, P. M., Smyth, F., Cardiff, B., \& Barry, L. P. (2012). Increased bit rate direct modulation AMO-OFDM transmission by optical injection using monolithically integrated lasers. IEEE Photonics Technology Letters, 24(11), 879-881. https://doi.org/10.1109/LPT.2012.2190049

DOI:

10.1109/LPT.2012.2190049

Document status and date:

Published: 01/01/2012

\section{Document Version:}

Publisher's PDF, also known as Version of Record (includes final page, issue and volume numbers)

\section{Please check the document version of this publication:}

- A submitted manuscript is the version of the article upon submission and before peer-review. There can be important differences between the submitted version and the official published version of record. People interested in the research are advised to contact the author for the final version of the publication, or visit the $\mathrm{DOI}$ to the publisher's website.

- The final author version and the galley proof are versions of the publication after peer review.

- The final published version features the final layout of the paper including the volume, issue and page numbers.

Link to publication

\section{General rights}

Copyright and moral rights for the publications made accessible in the public portal are retained by the authors and/or other copyright owners and it is a condition of accessing publications that users recognise and abide by the legal requirements associated with these rights.

- Users may download and print one copy of any publication from the public portal for the purpose of private study or research.

- You may not further distribute the material or use it for any profit-making activity or commercial gain

- You may freely distribute the URL identifying the publication in the public portal.

If the publication is distributed under the terms of Article 25fa of the Dutch Copyright Act, indicated by the "Taverne" license above, please follow below link for the End User Agreement:

www.tue.nl/taverne

Take down policy

If you believe that this document breaches copyright please contact us at:

openaccess@tue.nl

providing details and we will investigate your claim. 


\title{
Increased Bit Rate Direct Modulation AMO-OFDM Transmission by Optical Injection Using Monolithically Integrated Lasers
}

\author{
Colm Browning, Kai Shi, Sylwester Latkowski, Prince M. Anandarajah, \\ Frank Smyth, Barry Cardiff, and Liam P. Barry
}

\begin{abstract}
Experimental and simulation work, presented in this letter, demonstrates for the first time how the monolithic integration of two single-mode lasers in a master-slave configuration, can substantially increase the achievable bit rate of a direct modulation adaptively modulated optical orthogonal frequency-division multiplexing (AMO-OFDM) system. The Levin-Campello algorithm is applied to select the OFDM bit and power loading scheme used for each system configuration. Improvement in terms of data throughput due to injection is measured for several transmission distances with the improvement in performance presented in terms of error vector magnitude per OFDM subcarrier.
\end{abstract}

Index Terms-Direct modulation, optical access networks, optical injection, orthogonal frequency-division multiplexing.

\section{INTRODUCTION}

$\mathbf{T}$ HE exponential growth in demand for bandwidth due to increasing usage of multimedia services will require the deployment of cost effective higher speed optical networks. Orthogonal Frequency Division Multiplexing (OFDM) has been the subject of much research for use in these networks [1] due to its high spectral efficiency given by its overlapping, but orthogonal, subcarriers and high tolerance to dispersion. Dispersion is counteracted by the inclusion of a cyclic prefix (CP) which, provided the channel remains linear, ensures subcarrier orthogonality at the receiver and allows the signal to be detected with zero Inter Symbol (i.e. subcarrier) Interference (ISI). Another attractive attribute of OFDM is the ability to provide network flexibility in the form of dynamic bandwidth allocation which will be a key feature for future optical networks [2]. Furthermore, Adaptively Modulated Optical OFDM (AMO-OFDM) has the ability to maximise data throughput by adjusting the number of bits per subcarrier based on the set of subcarrier's channel Gain to Noise Ratio (GNR). These GNRs can be computed by the receiver with, for example, the aid of a channel training sequence.

It has been shown in [3] that Intensity Modulation Direct Detection (IMDD) AMO-OFDM has the potential to meet

Manuscript received November 11, 2011; revised February 17, 2012; accepted February 29, 2012. Date of publication March 6, 2012; date of current version April 20, 2012. This work was supported in part by the Science Foundation Ireland under the Principle Investigators and PIFAS Clusters Program.

The authors are with Rince Institute, Dublin City University, Dublin, Ireland (e-mail: colm.browning2@mail.dcu.ie).

Color versions of one or more of the figures in this letter are available online at http://ieeexplore.ieee.org.

Digital Object Identifier 10.1109/LPT.2012.2190049 the speeds required for these next generation networks. The use of directly modulated laser transmitters in these systems reduces both cost and footprint relative to transmitters which employ external modulators. Also, the problems of high insertion loss and polarization dependence are avoided. However, when directly modulating a laser, nonlinearity is introduced at certain frequencies due to nonlinear interactions between the carriers and the photons in the laser cavity. These frequencies are indicated by the resonant peak of the laser's modulation response [4]. The nonlinearity introduced upon direct modulation places a strict performance limit on the system as OFDM orthogonality depends greatly on the linearity of the channel. A proposed solution to this problem is to use optical injection to expand the linear region of operation of the directly modulated laser [5] and our previous work has shown how the use of injection can improve the performance of direct modulation OFDM systems by reducing system nonlinearity [6], [7]. Results presented here extend upon that work to show how AMO-OFDM can, with injection, be used to maximise achievable throughput, and how the adaptive LC algorithm performs with high levels of nonlinearity.

In this letter, we carry out optical injection using two discrete mode (DM) lasers which have been monolithically integrated, making the injection technique feasible for use in optical access networks. Results shown represent the first study of AMO-OFDM performance with such a device. Section II describes some device characteristics.

\section{Optical Injection With DM Laser DeVice}

The monolithically integrated device used in this letter consists of two DM laser diodes in a master-slave configuration. The DM laser diodes which have been manufactured using slotted ridge waveguide technology described in [8], have lower cost relative to DFB laser structures. The threshold current of the slave laser is $20 \mathrm{~mA}$ while the threshold of the master is $12 \mathrm{~mA}$ and biasing was set to 1.5 times and twice the threshold of the master and slave respectively. Figure 1a shows the modulation response of the device under the two operating conditions used for the experimental work. It can be seen that the resonant peak moves from $2.58 \mathrm{GHz}$ to $4.27 \mathrm{GHz}$ for these conditions when injection is used. Figure $1 \mathrm{~b}$ shows the result of an example two tone test for nonlinearity [9] at $3 \mathrm{GHz}$ performed for the device operating under noninjected and injected conditions, where the Optical Modulation 

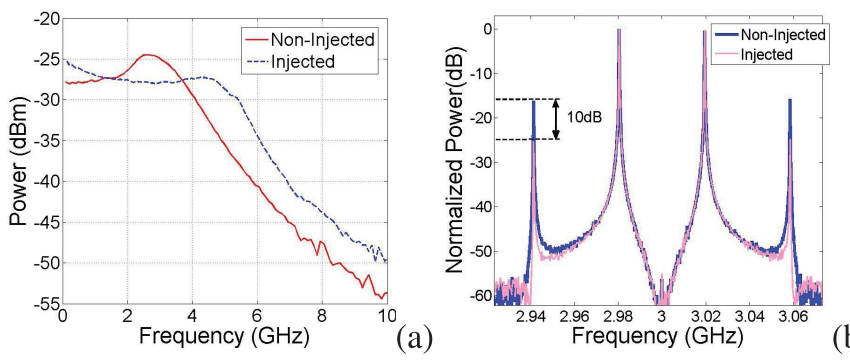

(b)

Fig. 1. (a) Modulation responses of the dual section-integrated device and (b) two tone test at $3 \mathrm{GHz}$ and with a tone spacing of $39.06 \mathrm{MHz}$.

Index (OMI) was $75 \%$. The power of the third order InterModulation Distortion (IMD3) products indicates the extent to which the two input tones have mixed due to nonlinearity and as such this test provides a gauge of nonlinearity within the system. It is evident from Fig. $1 \mathrm{~b}$ that a $10 \mathrm{~dB}$ reduction in IMD3, reduced from $-15 \mathrm{~dB}$ to $-25 \mathrm{~dB}$ relative to the fundamental, is achieved when optical injection is used. Tone spacing was set to the OFDM subcarrier spacing of $39.06 \mathrm{MHz}$.

\section{Simulation AND EXPERIMENT}

The Levin-Campello (LC) bit/power loading algorithm [10] was used to calculate a bit distribution across all subcarriers based on each subcarrier's GNR. A 256 Inverse Fast Fourier Transform (IFFT) was used with a subcarrier spacing of 39.06 MHz. The number of subcarries used, their respective power levels, and the constellation sizes are determined for each system configuration by use of the LC algorithm. This algorithm uses measured subcarrier GNRs which are determined by the use of an OFDM training sequence. Typically 100 subcarriers were used yielding a signal bandwidth of $3.9 \mathrm{GHz}$ and a peak-to-average power ratio of $12 \mathrm{~dB}$, however this varied slightly depending on the specifics of the system under test. After the IFFT operation a CP of $6.25 \%$ was added, a 'real' signal was created by modulating the complex baseband OFDM signal with the In-phase (I) and Quadrature (Q) components of an RF carrier signal.

Simulation: This system was first modeled in Matlab. Direct modulation of a laser was simulated by implementing the laser rate equations described in [11]. Optical injection was simulated by adding the relevant injection terms to these equations. Propagation through SSMF was modeled using the Non Linear Schrödinger Equation (NLSE) which incorporates the effects of nonlinearity, dispersion and attenuation. This equation was solved in discrete steps using the split step Fourier method. The modeled receiver comprised of a photodetector and Transimpedance Amplfier (TIA) with shot and thermal noise, low pass filtering, a digital RF mixer and required OFDM Digital Signal Processing (DSP).

Experimental Setup: The experimental set up is shown in Fig. 2. The experiment was performed for the non-injected and injected cases with the drive currents to the two lasers as outlined earlier. Detuning was $+10 \mathrm{GHz}$ when the master section of the device was biased at $24 \mathrm{~mA}$. The optical launch power increased from $-3.7 \mathrm{dBm}$ to $-1 \mathrm{dBm}$ when both master and slave are biased. OFDM pilots and the resultant AMOOFDM signals were output from the Digital to Analogue Con-

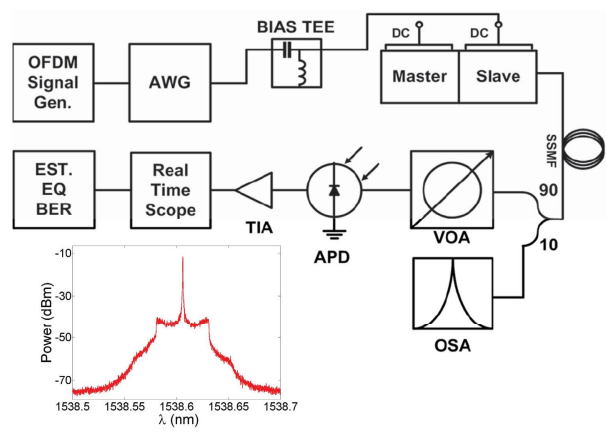

Fig. 2. Experimental setup with inset showing the received optical spectrum with OFDM data.

TABLE I

INCREASE IN BIT RATE GAINED BY OPTICAL INJECTION

\begin{tabular}{cccc}
\hline Distance $(\mathrm{km})$ & $\begin{array}{c}\text { Non- } \\
\text { Injected }(\mathrm{Gb} / \mathrm{s})\end{array}$ & Injected $(\mathrm{Gb} / \mathrm{s})$ & Improvement \\
\hline (Simulated) & & & \\
0 & $14.1(12.45)$ & $17.578(15.52)$ & $25 \%$ \\
25 & $12.227(10.8)$ & $16(14.13)$ & $31 \%$ \\
50 & $11.6(10.24)$ & $14.12(12.47)$ & $22 \%$ \\
\hline (Experimental) & & & \\
0 & $13.359(11.8)$ & $17.54(15.49)$ & $31 \%$ \\
25 & $12.109(10.69)$ & $15.76(13.86)$ & $30 \%$ \\
50 & $11.914(10.52)$ & $13.9(12.27)$ & $17 \%$ \\
\hline
\end{tabular}

verter (DAC) of the $10 \mathrm{GSa} / \mathrm{s}$ Tektronix Arbitrary Waveform Generator (AWG), giving an available bandwidth of $5 \mathrm{GHz}$ due to the Nyquist criterion. The signals were used to drive the slave section of the device after a bias of $30 \mathrm{~mA}$ had been added. The optical signal was then transmitted over different lengths of SSMF before being attenuated to an appropraite level for detection by a Variable Optical Attenuator (VOA). An Avalanche Photodetector (APD) with an integrated TIA was used for signal detection. The electrical signal was captured using an Agilent Real Time Oscilloscope (RTS) operating at $10 \mathrm{GSa} / \mathrm{s}$. Signal processing such as channel estimation, EQ, EVM and BER measurement was completed offline.

\section{Results AND Discussion}

Table I presents experimental and simulated raw data rates that can be achieved while maintaining a BER of $1 \times 10^{-3}$. The actual data rates, taking into account the CP (6.25\%) and forward error correction (FEC) $(7 \%)$ overheads are given in brackets. Also shown is the percentage improvement in terms of data rate. The experimental rates were achieved for a received optical power of $-17 \mathrm{dBm}$ giving an optical power budget of (13.3)16dBm in the (non)injected case. Higher optical power resulted in the saturation of the receiver.

In all cases a significant improvement in achievable data rate is evident after optical injection and this is matched in the simulated results. As transmission distances are increased the improvements are lessened due to the double sideband nature of the signal which results in dispersive fading over longer lengths of fibre [12]. As dispersive fading begins to dominate system performance, the relative improvement gained by injection becomes less evident. 


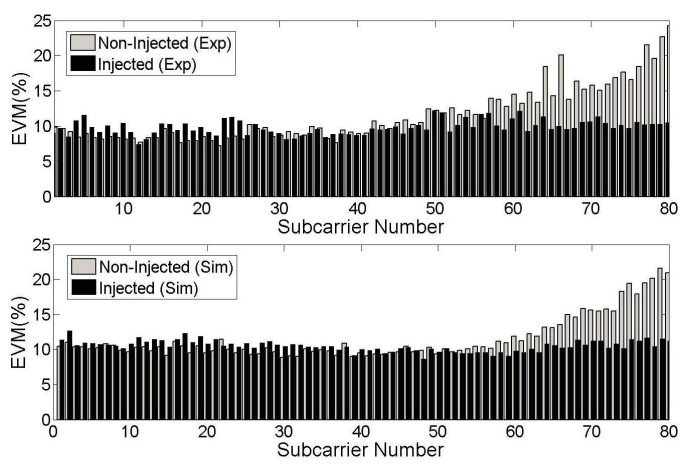

Fig. 3. Average EVM on each subcarrier under both operating conditions over $25 \mathrm{~km}$. RF center frequency was $1.8 \mathrm{GHz}$.

Figure 3 shows the experimental and simulated EVM per subcarrier over $25 \mathrm{~km}$ of SSMF for both operating conditions respectively. When the slave section alone is lasing the EVM increases rapidly up to as high as $24 \%$ as the subcarrier frequencies rise to within the nonliner region of operation of the device. This rise in EVM with frequency is stemmed when optical injection is employed. As the linear region of operation is expanded due to injection, the rise in EVM is greatly reduced and this is clear from both the experimental and simulated measurments. It is important to note that the EVM per subcarrier of the pilot OFDM signal used by the LC algorithm to facilitate power/bit loading may differ from that shown in Figure 3 in the presence of nonlinearity. This effect is discussed later in the section.

Figure 4 shows the experimental bit/power distribution assigned by the LC algorithm, again for both operating conditions, when the transmission distance is $25 \mathrm{~km}$. The effect of directly modulating data within the nonlinear region of the device is evident as the number of bits per QAM symbol (effective bit/power loading) reduces to QPSK at the upper subcarriers in the non-injected case. A decrease is also evident in the injected case but it is not as drastic, eventually reducing from six bits per QAM symbol (64-QAM) to four (16-QAM).

When assigning a bit distribution the LC algorithm calculates incremental energies required on each subcarrier to move to different QAM orders based on information about the channel (measured GNR on each subcarrier) as described in section III. A problem arises when subcarriers interact as is the case in a nonlinear channel. Initially a pilot signal with 16-QAM is proagated and the GNR measured for each subcarrier includes the noise contribution due to subcarrier mixing caused by nonlinearity. However when the bit distribution is updated by the LC algorithm the effect is to power load different subcarriers, or in some cases to drop subcarriers completely, according to their individual GNRs. Thus in the presence of nonlinearity these power/bit loaded subcarriers will not interact in exactly the same way as indicated by the pilot signal. We are currently carrying out work to adapt the LC algorithm to take into account the nonlinear characteristics of the optical channel.

\section{CONCLUSION}

It has been shown that the linear region of operation of a monolithically integrated DM laser can be expanded by optical

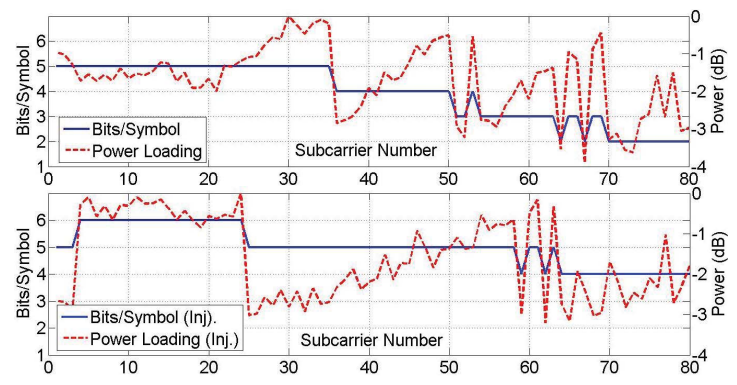

Fig. 4. Bit and power loading across all subcarriers, over $25 \mathrm{~km}$, with bits/symbol and normalized power on the $y$-axis.

injection. It has been demonstrated, experimentally and by simulation, that by using this technique in conjunction with the LC bit/power loading algorithm for a given BER, AMOFDM signal bit rates can be increased. Analysis of the effect of modulating an AM-OFDM signal in the nonlinear region of operation of the laser and how this effect is reduced upon injection is presented with strong agreement existing between the experimental and simulated results.

The optical injection technique, which has been shown to improve the performance of a direct modulation OFDM system, can be employed using any laser transmitter. The use of monolithic integration of two DM lasers makes the injection technique feasible for cost effective optical communications because of its footprint, cost and polarization independence.

\section{REFERENCES}

[1] J. Armstrong, "OFDM for optical communications," J. Lightw. Technol., vol. 27, no. 3, pp. 189-204, Feb. 1, 2009.

[2] D. Qian, N. Cvijetic, J. Hu, and T. Wang, "108 Gb/s OFDMA-PON with polarization multiplexing and direct detection," J. Lightw. Technol., vol. 28, no. 4, pp. 484-493, Feb. 15, 2010.

[3] T. Duong, et al., "Very high bit rate transmission for NGPON using AMOOFDM direct modulation of linear laser," in Proc. OFC, 2010, pp. $1-3$.

[4] G. van Tartwijk and D. Lenstra, "Semiconductor lasers with optical injection and feedback," Quantum Semiclass. Opt., vol. 33, no. 2, p. 90, Apr. 1995.

[5] X. J. Meng, T. Chau, and M. Wu, "Experimental demonstration of modulation bandwidth enhancement in distributed feedback lasers with external light injection," Electron. Lett., vol. 34, no. 21, pp. 2031-2032, Oct. 1998.

[6] C. Browning, et al., "Performance improvement of $10 \mathrm{~Gb} / \mathrm{s}$ direct modulation ofdm by optical injection using monolithically integrated discrete mode lasers," in Proc. 37th ECOC, Sep. 2011, pp. 1-3.

[7] C. Browning, et al., "Performance improvement of $10 \mathrm{~Gb} / \mathrm{s}$ direct modulation OFDM by optical injection using monolithically integrated discrete mode lasers," Opt. Express, vol. 19, no. 26, pp. B289-B294, Dec. 2011.

[8] C. Herbert, et al., "Discrete mode lasers for communication applications," Optoelectron., IET, vol. 3, no. 1, pp. 1-17, Feb. 2009.

[9] X. J. Meng, T. Chau, and M. Wu, "Improved intrinsic dynamic distortions in directly modulated semiconductor lasers by optical injection locking," IEEE Trans. Microw. Theory Tech., vol. 47, no. 7, pp. 1172 1176, Jul. 1999.

[10] J. Campello, "Optimal discrete bit loading for multicarrier modulation systems," in Proc. IEEE Int. Symp. Inf. Theory, Aug. 1998, p. 193.

[11] G. Agrawal and N. K. Dutta, Long-Wavelength Semiconductor Lasers. New York: Van Nostrand, 1986.

[12] G. Meslener, "Chromatic dispersion induced distortion of modulated monochromatic light employing direct detection," IEEE J. Quantum Electron., vol. 20, no. 10, pp. 1208-1216, Oct. 1984. 